\title{
Seroprevalence and Potential Risk Factors of Hepatitis E Virus among Pregnant Women in Khartoum, Sudan
}

\author{
Alaa Abdulrahman Mohammad Mustafa ${ }^{1}$ (D) Wafaa Mohammed Abdalla ${ }^{1}$ (D), \\ Hind Haidar Ahmed ${ }^{1}$, Samar M. Saeed ${ }^{1}$ D , Ahmed Ibrahim Hashim ${ }^{1}$ (D), \\ Sarrah Elnoor Khalifa ${ }^{1}$, Ahmed Bakheet AbdAlla², Tagwa Salah Ahmed ${ }^{3}$ \\ and Kashaf Junaid ${ }^{3 *}$ (D) \\ ${ }^{1}$ Department of Microbiology, College of Medical Laboratory Science, Sudan University of Science and \\ Technology, Sudan. \\ ${ }^{2}$ Department of Parasitology and Medical Entomology, College of Medical Laboratory Science, \\ Sudan University of Science and Technology, Sudan. \\ ${ }^{3}$ Department of Clinical Laboratory Sciences, College of Applied Medical Sciences, Jouf University, \\ Al Jouf 72388, Saudi Arabia.
}

\begin{abstract}
Although hepatitis E virus (HEV) infection has been widely understood as a public health concern in pregnant females, it is sometimes overlooked because of unusual observations of hepatitis E-induced complications during pregnancy. The objective of this descriptive cross-sectional study was to find out how frequent Hepatitis E virus infection is in pregnant women in Sudan. Blood samples were collected from pregnant women $(n=90)$ attending Khartoum North Hospital from February to December 2019. The specimens were investigated for Hepatitis $\mathrm{E}$ virus IgG and IgM antibodies using the commercial kits based on the enzyme immunosorbent assay (ELISA) technique. Out of ninety pregnant women, $36(40 \%)$ were found positive for IgG antibodies, and $5(6 \%)$ were tested positive for IgM antibodies. In addition, $13(14.5 \%)$ of the positive cases are women in their third trimester. These data showed a significant association between previous Hepatitis $E$ virus infection and miscarriage $(p<0.001)$. This study did not find a significant association between maternal and gestation age, education, water sources, and hepatitis E virus infection. In conclusion, there was a high percentage of HEV infections among pregnant women attending Khartoum North Hospital. This study estimates the Hepatitis E virus burden in Khartoum state, but more extensive studies are required to confirm the burden in Sudan.
\end{abstract}

Keywords: Hepatitis, Pregnancy, Viral infection, ELISA

*Correspondence: kashaf_junaid@hotmail.com

(Received: December 15, 2021; accepted: January 20, 2022)

Citation: Mustafa AAM, Abdalla WM, Ahmed HH, et al. Seroprevalence and Potential Risk Factors of Hepatitis E Virus among Pregnant Women in Khartoum, Sudan. J Pure Appl Microbiol. 2022;16(1):585-592. doi: 10.22207/JPAM.16.1.57

(C) The Author(s) 2022. Open Access. This article is distributed under the terms of the Creative Commons Attribution 4.0 International License which permits unrestricted use, sharing, distribution, and reproduction in any medium, provided you give appropriate credit to the original author(s) and the source, provide a link to the Creative Commons license, and indicate if changes were made. 


\section{INTRODUCTION}

Hepatitis E virus (HEV) is a common viral agent that causes acute viral hepatitis across the globe. More than 20 million HEV-infected cases are annually projected worldwide, with 70,000 casualties and 3,000 stillbirths expected each year. ${ }^{1,2}$ The hepatitis $E$ virus was discovered around 1978 during an outbreak across north India's Kashmir region, which resulted in 52,000 hepatitis cases and 17,000 deaths. ${ }^{3,4}$ Hepatitis $E$ has been found in at least 63 countries, either sporadically or as disease outbreaks. ${ }^{2,5}$

Hepatitis $E$ virus is a nonenveloped icosahedral virion with single-stranded positive polarity RNA. HEV belongs to the Hepeviridae family of viruses. HEV causes an acute, self-limiting disease in the general population, comparable to certain other acute viral hepatitis, like hepatitis $A$ or $B$, with a fatality rate of 0.2 to $1 \% \cdot{ }^{6}$ The most common cause of acute hepatitis and jaundice in the world is most likely HEV infection..$^{7-9}$ Hepatitis $E$ virus infection was once thought to be a disease of resource-poor locations, with faecal-oral transmission primarily via contaminated water supplies and just a few cases linked to travel to endemic areas in high-resource countries. According to data collected over the last nearly 15 years, locally acquired HEV infections are common in developed countries. These genotype 3 or $4 \mathrm{HEV}$ autochthonous infections were initially thought to be zoonotic, linked to raw meat consumption or animal contact. However, transfusion of blood and blood products was later linked to many HEV genotype 3 infection incidences in affluent countries. HEV viraemia among healthy blood donors in numerous countries supports the possibility of blood-borne transmission. ${ }^{10-14}$

Nevertheless, the prognosis of hepatitis E during pregnancy differs from the modest self-limiting infection seen in other groups. HEV infection can progress to a severe clinical stage during pregnancy, resulting in fulminant liver failure, loss of pregnancy, and stillbirths. Because people with hepatitis-like symptoms are infrequently screened for the virus thus epidemiological data regarding HEV infection during pregnancy is limited. ${ }^{15}$ On the other hand, HEV infection is thought to be responsible for between 2400 and 3000 stillbirths annually, in addition to fetal fatalities associated with prenatal maternal deaths. . $^{16,17}$

Even though these complications of HEV infections are well known in pregnancy, little is known about the exact viral mechanism of pathogenesis that produces it. It is reported that cytopathic effects of HEV by immune-mediated pathogenesis appear to be the cause of such severe problems during pregnancy. Pregnancyrelated alterations further influence the etiology of HEV in immune and hormonal responses. More research is required to learn about the underlying mechanisms. ${ }^{18,19}$

Hepatitis $\mathrm{E}$ has traditionally been known to be a disease of developing countries, where breakouts are more frequent due to a lack of safe drinking water. ${ }^{20}$ Acute hepatic failure owing to HEV infection is prevalent in pregnancy in these regions where HEV is prevalent, with a death incidence of approximately $20 \%{ }^{21,22}$ The first HEV outbreak, which included symptomatic pregnant women, occurred in Nepal's Kathmandu Valley in 1987. ${ }^{23}$

Recent epidemics have occurred in refugee camps with densely populated areas and inadequate sanitation in Somalia, Kenya, Sudan, and Uganda. ${ }^{24,25} \mathrm{HEV}$ monitoring in all regions worldwide is essential to build a consensus of this viral infection in pregnancy to give proper public health education.

In Sudan, the first cases of HEV infection were documented in 1992. Since then, there have been numerous more large outbreaks, mainly in Darfur refugee camps. Additionally, most of these outbreaks are linked to high maternal mortality rates. ${ }^{22}$

Despite the fact that $\mathrm{HEV}$ is widespread in various African nations, including Sudan, the true extent of HEV infection is unknown. The purpose of the study was to find out if pregnant women in Sudan were infected with HEV.

\section{MATERIALS AND METHODS \\ Study design}

This descriptive, cross-sectional, hospitalbased study targeted all pregnant women who attended Khartoum North Hospital in Khartoum State from February 2019 to December 2019. Participants were informed about the study's aims 
and written, or informed consent was taken. The study was approved by the Scientific Research Committee, College of Medical Laboratory Science, Sudan University of Science and Technology (SRCMLS-11-18). Fig. 1 depicts the area of the study.

\section{Data and specimen collection}

Data was collected by direct interview (questionnaire) with each participant, questionnaire was initially validated by conducting a pilot study. Ninety blood specimens were collected from each participant through the venous puncture, and blood was allowed to clot. Serum was obtained by centrifugation at $3000 \mathrm{rpm}$ for 15 minutes then stored at $-20^{\circ} \mathrm{C}$ until further investigation performance of the test.

Enzyme Linked Immuno-sorbant Assay (ELISA)

According to the manufacturer's instructions (EUROIMMUN), the technique was carried out with $100 \mu \mathrm{L}$ of calibrators, positive and negative controls, and diluted patient sera dispensed into designated wells of a 96well microtiter plate. The microtiter plate was incubated at room temperature for 30 minutes and then washed three times with the washing buffer. Afterward, $100 \mu \mathrm{L}$ of the enzyme conjugate provided with the kit was added to all the wells, and the washing step was repeated after incubation of 30 minutes. In each microplate well, $100 \mu \mathrm{L}$ of chromogen substrate solution was added and kept for 15 minutes at room temperature, preventing direct light. Finally, all wells were filled with $100 \mu \mathrm{L}$ of sulphuric acid to terminate the reaction. Following 30 minutes of introducing the stop solution, the optical density was measured spectrophotometrically with an ELISA reader at $450 \mathrm{~nm}$ and reference wavelengths of $620 \mathrm{~nm}$ and $650 \mathrm{~nm}$.

The results were assessed semiquantitatively by calculating a ratio of each sample's extinction value over the calibrator extinction value using the formula inside the leaflet. Wells with a ratio more than or equal to 1.1 were deemed positive, while those with a ratio less than 0.8 were classified negative. The kit is $100 \%$ sensitive and specific with the detection limit of $0.1 \mathrm{lU} / \mathrm{ml}$.

\section{Data analysis}

Data analysis was done using Statistical Package for Social Science (SPSS) software version 23. Frequencies were presented in the form of tables and figures. The significance of differences was determined using the Chi-square test, and statistical significance was established at $P$-value $\leq 0.05$.

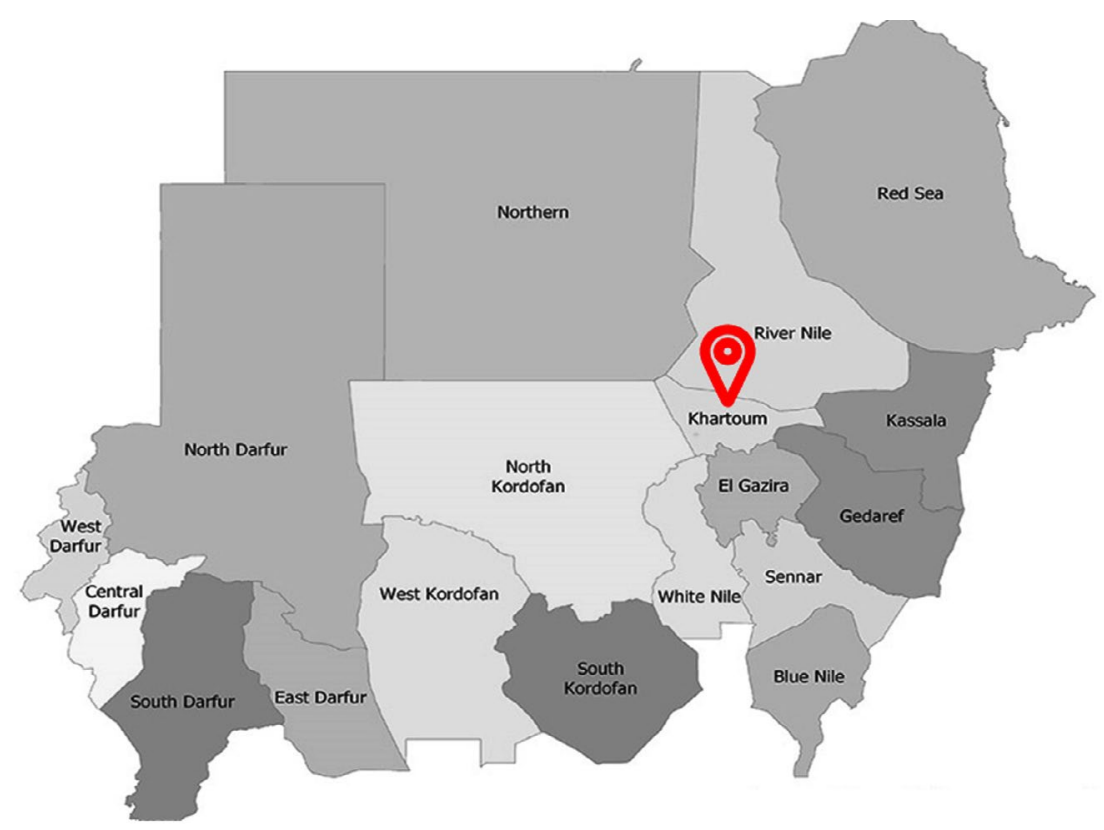

Fig. 1. Map of Sudan highlighting the study site 


\section{RESULTS}

In this study, 90 blood samples from Sudanese pregnant women were analyzed to detect HEV antibodies. The sociodemographic and clinical data of participants are presented in Table 1. The age ranged from 19 to 42 years, and the mean age for the pregnant female was $30.5 \pm$ 5.0 s.d. Based on the age of females, we divided them into three groups, and it was observed that the highest number of pregnant female $33(44.4 \%)$ participants belonged to the age group 19-26 years. It was also recorded that most pregnant females in this region were educated $60 \%$, and 40 were illiterate. The data revealed that almost
$68.9 \%$ of females drink nonfiltered water. Clinical data of the participants showed that $34.4 \%$ of females had a history of miscarriage. Out of 90 , $26(28.9 \%)$ were in the first trimester, while 26 (28.9\%) and $38(42.2 \%)$ were in the second and third trimester, respectively.

Frequency of HEV infection in pregnant female

Fig. 2 showed that out of 90 pregnant women, 36 (40\%) were found positive for IgG antibodies, and $5(6 \%)$ were tested positive for IgM antibodies. All anti-HEV IgM seropositive samples were also anti-HEV IgG positive. It was also observed that for acute hepatitis $E$ infection, out of 5 positive cases, $60 \%$ were in the third trimester,

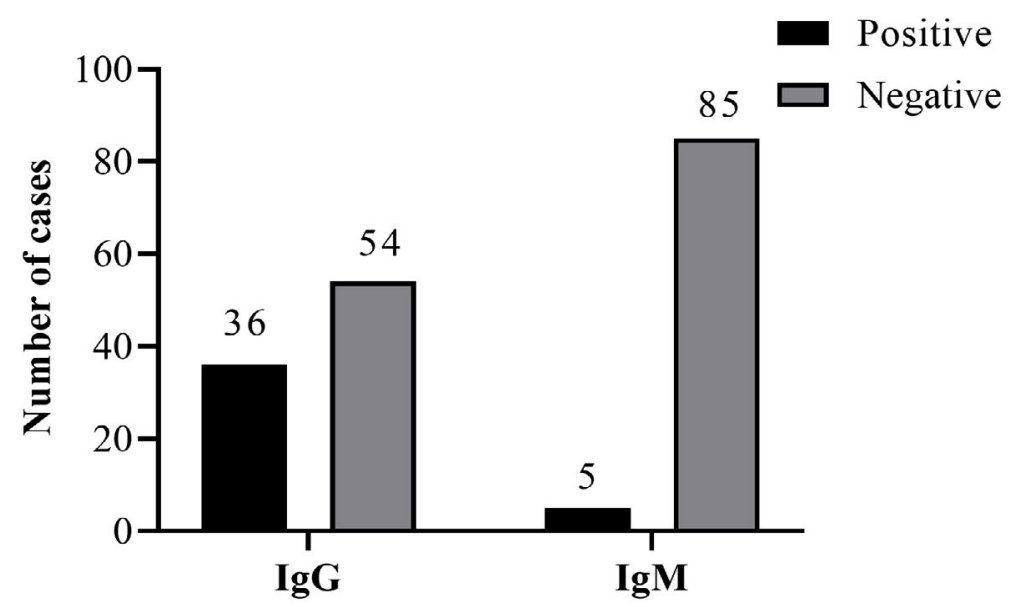

Fig. 2. Frequency of anti-HEV IgM and IgG antibodies among pregnant women.

a

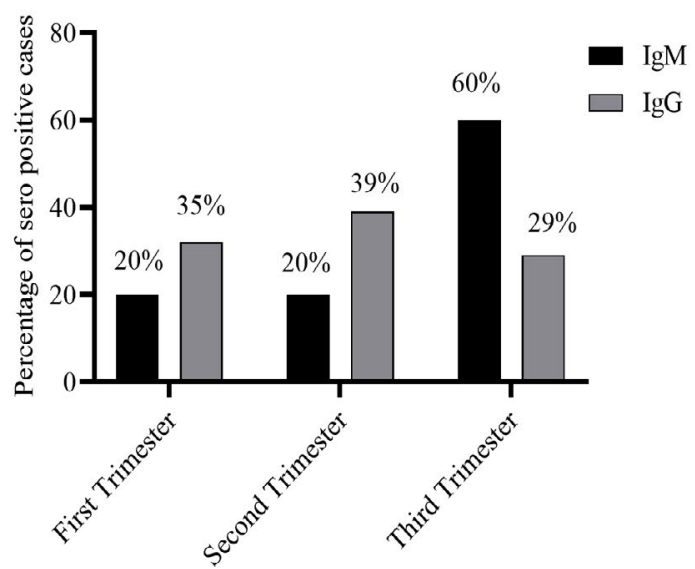

b

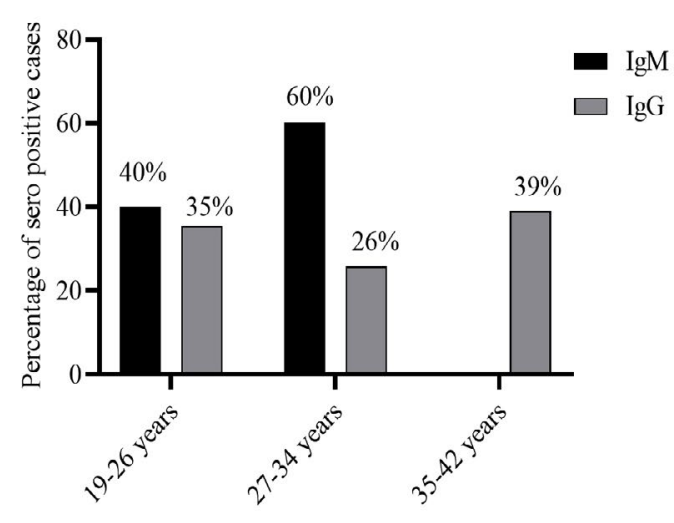

Fig. 3. Frequency of anti-HEV IgM and IgG antibodies among pregnant women according to gestational and mother age. 
and age belonged $27-34$ years. Not a single acute case was reported in females aged 35-42 years. On the other side for IgG, a high proportion was seen in the second trimester, and age belonged to 35-42 years (Fig. 3).

Risk factors associated with the HEV IgG positivity among study subjects

Regression analysis was done to find any association of risk factors with HEV IgG

Table 1. Demographic and socioeconomic characteristics $(n=90)$

\begin{tabular}{lc}
\hline Variable & $\mathrm{N}(\%)$ \\
\hline Age & $33(36.7 \%)$ \\
$19-26$ years & $30(33.3 \%)$ \\
$27-34$ years & $27(30 \%)$ \\
$35-42$ years & \\
Education & $36(40 \%)$ \\
Illiterate & $54(60 \%)$ \\
Educated & \\
Drinking water & $28(31.1 \%)$ \\
Filtered & $62(68.9 \%)$ \\
Non filtered & \\
History of miscarriage & $31(34.4 \%)$ \\
Yes & $59(65.5 \%)$ \\
No & \\
Gestational age & $26(28.9 \%)$ \\
First trimester & $26(28.9 \%)$ \\
Second trimester & $38(42.2 \%)$ \\
Third trimester & \\
\hline
\end{tabular}

seropositivity in pregnant females, and results are presented in Table 2. Out of the 90 pregnant women and considering age groups; HEV IgG was positive in 13/33 (14.4\%) among age group (19$26)$ years, $11 / 30(12.3 \%)$ tested positive among $(27-34)$ years, and $12 / 27$ (13.3\%) were positive among (35 to 42 ) years, and the age was no significant association between age groups and HEV infection. Our findings revealed that; $36 \%$ of the pregnant women who tested positive for HEV were in the third trimester, $33 \%$ and $31 \%$ were in the first and second trimester, respectively. A high proportion of seropositive cases were observed in the third trimester but were not statistically significant.

Considering the educational level, the results showed that; 20 (55.5\%) of educated women were positive for HEV antibodies, while $16(44.5 \%)$ of non-educated tested women were positive for HEV antibodies. Our analysis showed no significant association $(P=0.482)$ between education and HEV infection.

This study found that 25 (69\%) of pregnant women who drank non-filtered water were positive for HEV antibodies, while 11 (31\%) of pregnant women who drank filtered water were positive, and there was no significant correlation $(P=0.926)$ between the source of water and HEV infection.

Table 2. Risk factors associated with the HEV IgG positivity among study subjects

\begin{tabular}{|c|c|c|c|c|c|}
\hline \multirow[t]{2}{*}{ Variable } & & \multicolumn{2}{|c|}{ HEV IgG Sero status } & \multirow[t]{2}{*}{$p$-value } & \multirow[t]{2}{*}{ OR $(95 \% \mathrm{Cl})$} \\
\hline & & $\begin{array}{c}\text { Positive } \\
(n=36)\end{array}$ & $\begin{array}{c}\text { Negative } \\
(n=54)\end{array}$ & & \\
\hline \multirow[t]{3}{*}{ Age } & $19-26$ years & $13(36 \%)$ & $20(37 \%)$ & - & - \\
\hline & $27-34$ years & $11(31 \%)$ & $19(35 \%)$ & 0.82 & $0.89(0.32-2.46)$ \\
\hline & $35-42$ years & $12(33 \%)$ & $15(28 \%)$ & 0.69 & $1.23(0.43-3.45)$ \\
\hline \multirow[t]{3}{*}{ Gestational age } & First Trimester & $11(31 \%)$ & $20(37 \%)$ & - & - \\
\hline & Second Trimester & $12(33 \%)$ & $17(31.5 \%)$ & 0.53 & $1.39(0.49-3.89)$ \\
\hline & Third Trimester & $13(36 \%)$ & 17 (31.5\%) & 0.63 & $1.28(0.45-3.64)$ \\
\hline \multirow[t]{2}{*}{ Education } & Educated & $20(55.5 \%)$ & 34 (62.9\%) & 0.48 & $1.36(0.57-3.20)$ \\
\hline & Illiterate & $16(44.5 \%)$ & $20(37.1 \%)$ & & \\
\hline Number of & $1^{\text {st }}$ pregnancy & $10(27.7 \%)$ & $18(33.3 \%)$ & 0.59 & $0.75(0.26-2.12)$ \\
\hline \multirow[t]{2}{*}{ pregnancies } & $2-3$ & $12(33.3 \%)$ & 17 (31.5\%) & 0.93 & $0.95(0.34-2.6)$ \\
\hline & More than 3 & $14(39 \%)$ & 19 (35.2\%) & - & - \\
\hline \multirow[t]{2}{*}{ Drinking water } & Filtered water & $11(31 \%)$ & $17(30 \%)$ & 0.92 & $1.04(0.38-2.38)$ \\
\hline & Non-filtered water & $25(69 \%)$ & $37(70 \%)$ & & \\
\hline History of & Yes & $22(61 \%)$ & $9(17 \%)$ & 0.001 & 7.85 (2.95-20.94) \\
\hline Miscarriage & No & $14(39 \%)$ & 45 (83\%) & & \\
\hline
\end{tabular}


In addition, 22/36 (61\%) cases had a history of miscarriage, indicating a significant association between previous $\mathrm{HEV}$ infection and miscarriage $(\mathrm{P}<0.000, \mathrm{OR}=7.85,95 \% \mathrm{Cl}: 2.95$ 20.94).

\section{DISCUSSION}

Despite the significance of HEV infection, few research have been conducted in Sudan to explore its prevalence and implications, particularly in pregnant women. The goal of this study was to find out if pregnant women were infected with HEV. We found that 36/90 (40\%) pregnant women were anti- HEV positive. Our finding is consistent with previous studies conducted in Ethiopia (43.4\%) and Nigeria (42.7\%). ${ }^{26,27}$ Our results also revealed that; the prevalence of infected pregnant women in Sudan is higher than in Ghana (12.3\%) and in France (7.74\%). ${ }^{28-30}$

Interestingly, another study conducted in Sudan- Darfur showed that $95 \%$ of pregnant women under investigation were infected with HEV. ${ }^{31}$ Our analysis indicates that the prevalence of HEV-infected pregnant women in Darfur is twice that of infected pregnant women in Khartoum. The possible explanation for this variation is that Darfur state suffered from conflict and humanitarian crisis for a decade. As a result, most Darfur population lives in refugee camps where access to healthy food and clean water is almost impossible. Such conditions provide a great environment for disease outbreaks.

Our study found that $5.6 \%$ of pregnant women were anti- IgM positive, indicating recent infection with HEV. Different studies worldwide investigated the presence of recent HEV infections in pregnant women, and the findings were variable ranging from (0.2-64.40\%). Perhaps, these variances could be due to differences in the level of hygiene, educational status, social status, endemicity of the virus, and different lifetime exposures of the participants to HEV. Our finding was higher than the results obtained in Ghana (0.2\%) and Ethiopia (0.9\%). ${ }^{26,28,32}$ This study's rate of seropositivity, on the other hand, was lower than that reported by Adjei et al. in Ghana, which was 64.40 percent. ${ }^{29,33}$

In our attempt to identify the previous infection with HEV within the study population, we investigated the prevalence of HEV IgG antibodies among pregnant women. We found that $40 \%$ of the cases are positive for HEV IgG antibodies. These findings are consistent with those obtained by another study in Khartoum, Sudan (41.1\% (37/90) and other studies from Africa; in Nigeria (42.7\%) of pregnant women were positive for IgG antibodies, followed by (42.4\%) in Ethiopia and (35.60\%) in Ghana. $27,29,33$ Other investigators observed a lower frequency of IgG antibodies from different countries, with the lowest percentage of $0.22 \%$ in Lebanon and $31 \%$ in Ethiopia. ${ }^{28,34}$ Compared to our study Dawoud et al in Sudan detected anti-HEV IgG antibodies in $61.2 \%$ of the study subjects and reported lower seropositivity rates of IgG antibodies in Sudan. Such variations between countries could be attributed to many reasons but not limited to socioeconomic reasons, access to health clinics, clean water, and healthy food. Finally, the greatest ways to reduce the morbidity of HEV infection and many other waterborne infections is to prevent virus transmission through adequate sanitation and boiling drinking water.

Our study noted that most HEV-positive cases are in their third trimester, followed by the second and first trimester. That women can explain such findings in their third trimester are highly susceptible to HEV infection and other infections. ${ }^{33}$

Several studies investigated the potential of HEV as a risk factor for miscarriage. In this study, HEV was significantly associated with previous miscarriages. This confirms the earlier findings that HEV infection is related to the last miscarriage reported 2016 in Sudan (36.8\%). ${ }^{35}$ Perhaps the possible reasons are that most of the reported studies are from developing countries where contaminated water sources and malnutrition are common. Besides that, women in their third trimester are more prone to HEV infection and virus transmission from mother to the fetus may occur, leading to severe complications including but not limited to stillbirth and abortion. Therefore, a screening program for HEV is highly recommended to be part of the routine tests for pregnant women. However, there are some limitations to this study. For instance, the sample size was low, and the virological investigation did not use molecular techniques. 


\section{CONCLUSION AND RECOMMENDATIONS}

In conclusion, we demonstrate that the incidence of HEV infection is high among pregnant women attending Khartoum North Hospital. Our studies found a significant association between $\mathrm{HEV}$ infection and previous miscarriage.

More studies are required to elucidate the association between HEV infection and previous miscarriage. To accurately establish the infection rate, a larger sample size and more reliable techniques (such as PCR) should be employed. Furthermore, to characterize the epidemiological patterns of HEV in terms of pathogenicity and severity, the floating HEV genotypes in the pregnant women of Sudan must be established.

\section{ACKNOWLEDGMENTS}

The authors would like to thank all the colleagues who helped in the study.

\section{CONFLICT OF INTEREST}

The author declares that there is no conflict of interest.

\section{AUTHORS' CONTRIBUTION}

All authors listed have made a substantial, direct and intellectual contribution to the work, and approved it for publication.

\section{FUNDING}

None.

\section{DATA AVAILABILITY}

All datasets generated or analyzed during this study are included in the manuscript.

\section{ETHICS STATEMENT}

The study was approved by the Scientific Research Committee, College of Medical Laboratory Science, Sudan University of Science and Technology, Sudan with reference number SRC-MLS-11-18.

\section{INFORMED CONSENT}

Written informed consent was obtained from the participants before enrolling in the study.

\section{REFERENCES}

1. Hakim MS, Wang W, Bramer WM, et al. The global burden of hepatitis $\mathrm{E}$ outbreaks: a systematic review.
Liver Int. 2017;37(1):19-31. doi: 10.1111/liv.13237

2. Rein DB, Stevens GA, Theaker J, Wittenborn JS, Wiersma ST. The global burden of hepatitis E virus genotypes 1 and 2 in 2005. Hepatology. 2012;55(4):988-997. doi: 10.1002/hep.25505

3. Pallerla SR, Harms D, Johne R, et al. Hepatitis E Virus Infection: Circulation, Molecular Epidemiology, and Impact on Global Health. Pathogens. 2020;9(10):856. doi: $10.3390 /$ pathogens9100856

4. Nimgaonkar I, Ding Q, Schwartz RE, Ploss A. Hepatitis E virus: advances and challenges. Nat Rev Gastroenterol Hepatol. 2018;15(2):96-110. doi: 10.1038/nrgastro.2017.150

5. Kar P, Sengupta A. A guide to the management of hepatitis $\mathrm{E}$ infection during pregnancy. Expert Review of Gastroenterology \& Hepatology. 2019;13(3):205211. doi: 10.1080/17474124.2019.1568869

6. Kamar N, Dalton HR, Abravanel F, Izopet J. Hepatitis E virus infection. Clin Microbiol Rev. 2014;27(1):116-138. doi: $10.1128 / \mathrm{cmr} .00057-13$

7. Sridhar S, Lo SK, Xing F, et al. Clinical characteristics and molecular epidemiology of hepatitis $E$ in Shenzhen, China: a shift toward foodborne transmission of hepatitis E virus infection. Emerg Microbes Infect. 2017;6(12):e115. doi: 10.1038/emi.2017.107

8. Baymakova M, Sakem B, Plochev K, et al. Epidemiological characteristics and clinical manifestations of hepatitis E virus infection in Bulgaria: A report on 20 patients. Srp Arh Celok Lek. 2016;144(1-2):63-68. doi: 10.2298/ sarh1602063b

9. Sato N, Watanabe S, Miura K, et al. Clinical and virologic features of hepatitis $E$ virus infection at a university hospital in Japan between 2000 and 2019. J Med Virol. 2020;92(12):3572-3583. doi: 10.1002/jmv.26248

10. Jupattanasin S, Chainuvati S, Chotiyaputta W, et al. A nationwide survey of the seroprevalence of hepatitis E virus infections among blood donors in Thailand. Viral Immunol. 2019;32(7):302-307. doi: 10.1089/ vim.2018.0146

11. Takeda H, Matsubayashi K, Sakata H, et al. A nationwide survey for prevalence of hepatitis $E$ virus antibody in qualified blood donors in Japan. Vox Sang. 2010;99(4):307-313. doi: 10.1111/j.14230410.2010.01362.x

12. Spada E, Pupella S, Pisani G, et al. A nationwide retrospective study on prevalence of hepatitis $E$ virus infection in Italian blood donors. Blood Transfus. 2018;16(5):413-421. doi: 10.2450/2018.0033-18

13. Baymakova M, Terzieva K, Popov R, et al. Seroprevalence of Hepatitis E Virus Infection among Blood Donors in Bulgaria. Viruses. 2021;13(3):492. doi: 10.3390/ v13030492

14. Mansuy JM, Gallian P, Dimeglio C, et al. A nationwide survey of hepatitis E viral infection in French blood donors. Hepatology. 2016;63(4):1145-1154. doi: 10.1002/hep.28436

15. Navaneethan U, Al Mohajer M, Shata MT. Hepatitis $E$ and pregnancy: understanding the pathogenesis. Liver Int. 2008;28(9):1190-1199. doi: 10.1111/j.14783231.2008.01840.x

16. Perez-Gracia MT, Suay-Garcia B, Mateos-Lindemann ML. Hepatitis E and pregnancy: current state. Rev Med 
Virol. 2017;27(3):e1929. doi: 10.1002/rmv.1929

17. Kamar N, Bendall R, Legrand-Abravanel $F$, et al. Hepatitis E. Lancet. 2012;379(9835):2477-2488. doi: 10.1016/s0140-6736(11)61849-7

18. Lee GY, Poovorawan K, Intharasongkroh D, et al. Hepatitis E virus infection: Epidemiology and treatment implications. World J Virol. 2015;4(4):343355. doi: 10.5501/wjv.v4.i4.343

19. Lhomme S, Marion O, Abravanel F, Izopet J, Kamar N. Clinical Manifestations, Pathogenesis and Treatment of Hepatitis E Virus Infections. J Clin Med. 2020;9(2):331. doi: $10.3390 / \mathrm{jcm} 9020331$

20. Ahmed A, Ali IA, Ghazal H, Fazili J, Nusrat S. Mystery of hepatitis e virus: recent advances in its diagnosis and management. Int J Hepatol. 2015;2015:872431. doi: $10.1155 / 2015 / 872431$

21. Acharya SK. Hepatitis $E$ and acute liver failure in pregnancy. J Clin Exp Hepatol. 2013;3(3):213-224. doi: 10.1016/j.jceh.2013.08.009

22. Elduma AH, Zein MM, Karlsson M, Elkhidir IM, Norder H. A Single Lineage of Hepatitis E Virus Causes Both Outbreaks and Sporadic Hepatitis in Sudan. Viruses. 2016;8(10):273. doi: 10.3390/v8100273

23. Shrestha A. Viral Hepatitis in Nepal: Past, Present, and Future. Euroasian J Hepatogastroenterol. 2016;6(1):59-61. doi: 10.5005/jp-journals-10018-1169

24. Bagulo H, Majekodunmi AO, Welburn SC. Hepatitis $E$ in Sub Saharan Africa - A significant emerging disease. One Health. 2020;11:100186. doi: 10.1016/j. onehlt.2020.100186

25. Kim JH, Nelson KE, Panzner U, Kasture Y, Labrique AB, Wierzba TF. A systematic review of the epidemiology of hepatitis E virus in Africa. BMC Infect Dis. 2014;14:308. doi: 10.1186/1471-2334-14-308

26. Niguse $\mathrm{S}$, Hailekiros $\mathrm{H}$, Buruh G, Dejene T, Berhe $\mathrm{N}$, Asmelash T. Seroprevalence and risk factors of Hepatitis E virus infection among pregnant women attending antenatal care in health facilities of Tigray, Northern Ethiopia. J Med Virol. 2018;90(8):1364-1369. doi: 10.1002/jmv.25190
27. Junaid SA, Agina SE, Abubakar KA. Epidemiology and associated risk factors of hepatitis e virus infection in plateau state, Nigeria. Virology. 2014;5:15-26. doi: 10.4137/VRT.S15422

28. Obiri-Yeboah D, Asante Awuku Y, Adu J, et al. Seroprevalence and risk factors for hepatitis $E$ virus infection among pregnant women in the Cape Coast Metropolis, Ghana. PLoS One. 2018;13(1):e0191685. doi: 10.1371/journal.pone.0191685

29. Adjei AA, Tettey Y, Aviyase JT, et al. Hepatitis E virus infection is highly prevalent among pregnant women in Accra, Ghana. Virol J. 2009;6:108. doi: 10.1186/1743422X-6-108

30. Renou C, Gobert V, Locher C, et al. Prospective study of Hepatitis E Virus infection among pregnant women in France. Virol J. 2014;11:68. doi: 10.1186/1743-422X11-68

31. Boccia D, Guthmann JP, Klovstad H, et al. High mortality associated with an outbreak of hepatitis $E$ among displaced persons in Darfur, Sudan. Clin Infect Dis. 2006;42(12):1679-1684. doi: 10.1086/504322

32. Abebe M, Ali I, Ayele S, Overbo J, Aseffa A, Mihret A. Seroprevalence and risk factors of Hepatitis $E$ Virus infection among pregnant women in Addis Ababa, Ethiopia. PLoS One. 2017;12(6):e0180078. doi: doi: 10.1371/journal.pone.0180078

33. Al-Tayeb ZA, Nafi M, Yassin MEM. Frequency of hepatitis $E$ virus among pregnant women attending Khartoum hospitals. Am J Res Commun. 2014;2(4):241247.

34. Ismail MB, Khodor S, Osman M, Mallat H, Dabboussi F, Hamze M. Seroprevalence of hepatitis E virus in pregnant women in northern Lebanon. East Mediterr Health J. 2020;26(5):580-585. doi: 10.26719/ emhj.19.103

35. Dawoud AA. Seroprevalence of hepatitis E Virus among pregnant women attending Wad Madani Teaching Hospital, Sudan. J Medical Biomed Sci. 2017;5(2):101107. doi: $10.15520 / . v 5 i 2.43$ 